This item was submitted to Loughborough's Research Repository by the author.

Items in Figshare are protected by copyright, with all rights reserved, unless otherwise indicated.

\title{
International business research and game theory: looking beyond the prisoner's dilemma
}

PLEASE CITE THE PUBLISHED VERSION

http://dx.doi.org/10.1016/j.ibusrev.2012.07.004

PUBLISHER

(C) Elsevier

VERSION

AM (Accepted Manuscript)

LICENCE

CC BY-NC-ND 4.0

\section{REPOSITORY RECORD}

Ott, Ursula F.. 2019. "International Business Research and Game Theory: Looking Beyond the Prisoner's Dilemma". figshare. https://hdl.handle.net/2134/15163. 
This item was submitted to Loughborough's Institutional Repository (https://dspace.lboro.ac.uk/) by the author and is made available under the following Creative Commons Licence conditions.

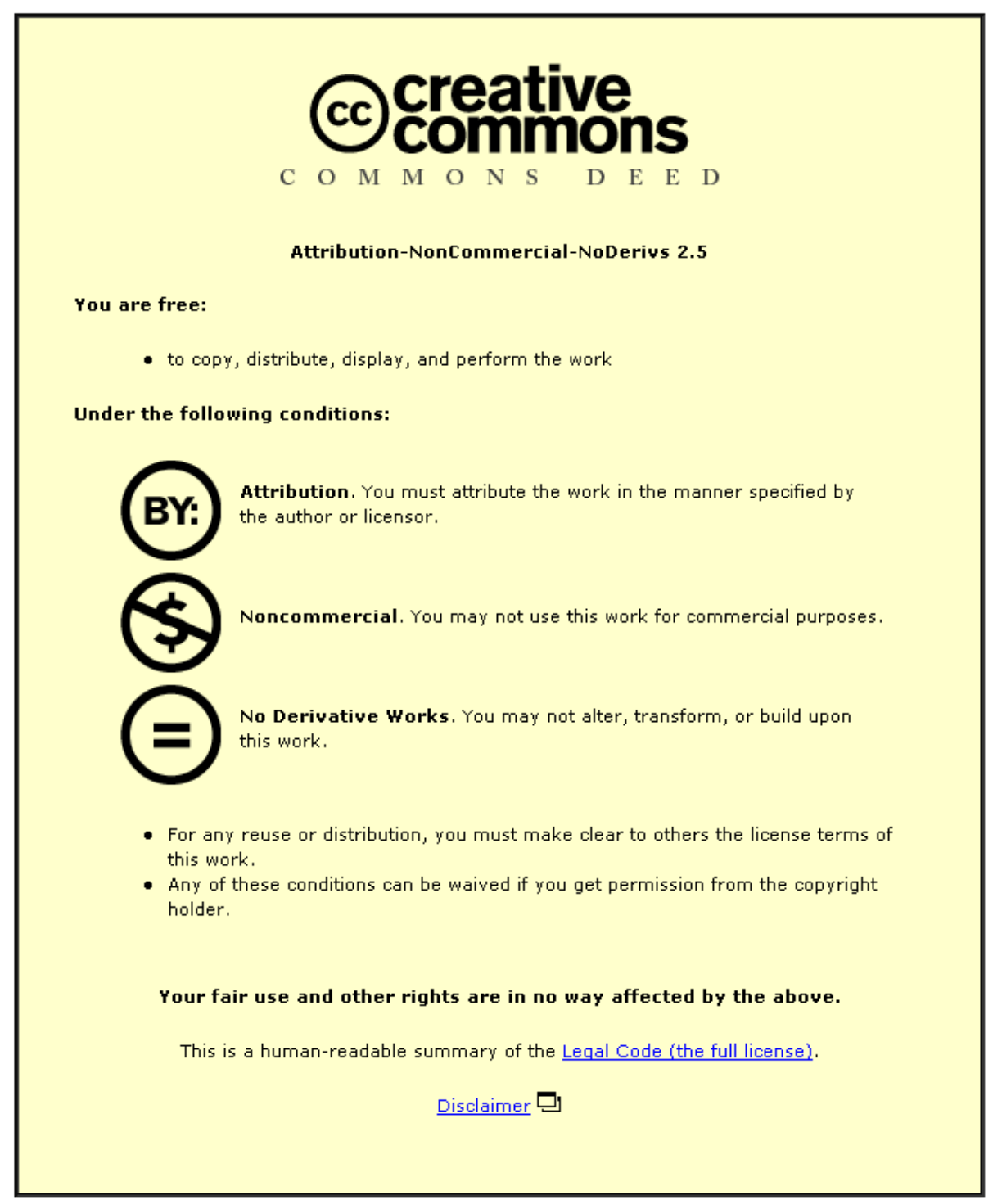

For the full text of this licence, please go to: http://creativecommons.org/licenses/by-nc-nd/2.5/ 


\title{
INTERNATIONAL BUSINESS RESEARCH AND GAME THEORY: LOOKING BEYOND THE PRISONER'S DILEMMA
}

\begin{abstract}
This article outlines the un-mined potential of Game Theory for International Business research. Game Theory has been only rarely used in International Business - particularly, in comparison to transaction cost economics and the resource based view. Although its applications to International Business problems do exist, there is considerably more potential for its refinements to be related to topics of uncertainty and dynamics in strategic interactions in International Business. There is more to Game Theory than the Prisoner's Dilemma.
\end{abstract}

Keywords: International Business Research Agenda, Research Methods, Game Theory, Multinational Enterprises, Emerging Markets, Culture 
1. Introduction

For a long time International Business topics of absolute, relative and competitive advantage have triggered political scientists, economists and social scientists to explore theories to understand the what, how and why questions of international trade, multinational enterprises and globalization. The field of International Business has always combined theoretical concepts from many disciplines. Phenomena and problems in International Business ask for tools to explain and solve them. Within the tension between different legal, political, cultural, organizational, economic and managerial systems, decision-making between individuals, groups, companies and countries plays a crucial role in International Business. This means that in a complex decision-making scenario, International Business research needs to draw upon tools which explain, analyze and solve these strategic interactions. In this article, we make the case for such a theoretical tool to analyze cooperation and conflict in International Business - Game Theory.

Game Theory cannot simply be viewed as a matter of abstract mathematics, but as fundamentally concerning the real world (Rubinstein, 1991).

Rubinstein's statement indicates that Game Theory is an abstract inquiry into the function and logic of social institutions and patterns of behavior. Game Theory offers a strategic tool to look forwards by reasoning backwards which can be very useful for decision-makers in multiperson decision-making situations like those in International Business. Schelling (1960) showed as much in the Strategy of Conflict a rational analysis of international political conflict - as did Axelrod (1984) in the Evolution of Co-operation, which showed how cooperation can emerge in a world of self-interested egoists (superpowers, businesses and individuals) without central authority to police action. Both conflict and co-operation are crucial parts of Game Theory and the strategic treatment of decision-making situations has contributed to a better understanding of behavior in social, political and economic settings. Though Game Theory is mostly equated to the Prisoner's Dilemma, this paper shows the 
potential of the solution concepts to analyze dynamics and uncertainty as well. The analysis of International Business problems and challenges, such as MNEs in emerging markets, can usefully import knowledge from other disciplines and then export the new insights gained from the applications to IB problems.

This paper shows the strength of Game Theory for considering international business problems. It starts with the chronology, explanations, notations and reasoning of Game Theory and reviews the applications of Game Theory to International Business. To understand the use of Game Theory for International Business, strength and weaknesses are presented in the framework of analysis to deal with the criticism often put forward against Game Theory. The contribution of this paper is that it connects the future IB research agenda suggested by IB scholars with the strength of a game theoretical approach as a mode of analysis. In the mathematical appendix the reader will find a formal example to support the argument for IB and Game Theory.

\section{Game Theory and International Business}

\subsection{Game Theory - Chronology, Explanations and Notations}

This section introduces the works of game theory and the basic notation and rules of the games as well as the solution concepts offered. The starting point for the development of Game Theory was the publication of John von Neumann and Oscar Morgenstern's seminal work 'The Theory of Games and Economic Behavior' in 1944. Subsequently, Economics and Political Science have been the main fields in which Game Theory has been applied and developed. Game Theorists became Nobel Laureates for Economics in 1994 (John Nash, Reinhard Selten and John Harsanyi), 1996 (James Mirrlees, William Vickrey), 2001 (George Akerlof, Michael Spence, Joseph Stiglitz), 2005 (Robert Aumann, Thomas Schelling), and 2007 (Leonid Hurwicz, Eric Maskin, Roger Myerson). By contrast, Game Theory has not 
been widely used in the field of Business. Camerer (1991) argued that the field of Strategic Management was considerably impaired by the way in which Game Theory had been marginalized within that field. In this paper, we take Camerer’s (1991) general approach, develop it, and apply it to the specific field of International Business.

\subsubsection{Games - Notation}

Game Theory can be divided into Co-operative and Non-cooperative Game Theory. The former is important in the context of coalitions and political science of voting. The latter has been necessary to examine static and dynamic games and games played with complete or incomplete information - chess or poker, for instance. Table 1 shows the relevant solution concepts in this context in a $2 \times 2$ table formed by the dimensions of time and information.

Game Theory has been widely defined as the study of mathematical models of cooperation and conflict (Myerson, 1991). A game, $\Gamma$, in game theoretical terms, is any social situation of two or more individuals who are called players $(\mathrm{N})$. These players are assumed to be rational and intelligent. A decision-maker is rational when she makes decisions consistently in pursuit of her own objectives. The players choose strategies, $C_{i}$, and their choice of strategies yields payoffs to each player (possibly random). In Game Theory, 'strategy' means the actions of the players. The term, 'strategy', should not be confused with the use of it in strategic management. Each player's objective is to maximize the expected value of her own payoff, which is measured in utility scale $u_{i}$. The basic model of a game is, therefore, $\Gamma=\left(N,\left(C_{i}\right)_{i \in N},\left(u_{i}\right)_{i \in N}\right)$.

Camerer's (1991) explication of the utility of Game Theory for Strategic Management Research distinguishes between games, game theoretic reasoning and equilibrium points which are determined by game-theoretic reasoning. He used Cournot quantity-setting and the 
centipede game as examples and dispelled a common myth that players who do not reason game theoretically will never converge to an equilibrium and another myth that players must think they are rational ad infinitum. When he suggested that game theory provides a taxonomy of interactive situations, it becomes clear that not only strategy research, but also International Business can benefit from using strategic formulation situations. He suggested the benefits of becoming familiar with the terms of game theory such as equilibrium, pooling and separating, rationalizability, reputation, folk theorem, coordination games, trigger strategies, learning curve, strategic groups, entry barriers and scope and scale economies (see glossary). A lot of these terms and concepts are used in International Business as well and merging them seems a useful way forward.

\subsubsection{Game Theoretic Reasoning}

We use Camerer's (1991) approach to look into game theoretic reasoning. Game theoretic reasoning is expressed in the decision rule or algorithm which selects the equilibrium strategy. Camerer used the Cournot-Nash equilibrium to show the quantity setting process of reasoning and the Centipede game to show the moves of the players and the algorithm which starts at the last possible move and works forward. This is seen as looking forwards and reasoning backwards - backward induction. Camerer mainly focused on Cournot and Centipede games, but there are many more equilibrium concepts, such as Bertrand Nash equilibrium (price setting equilibrium), Stackelberg equilibrium (leader-follower situation), Sub-Game Perfect equilibrium (sequential moves), Bayesian Nash equilibrium (uncertainty and simultaneous moves), Perfect Bayesian Equilibrium (uncertainty and dynamic updating of beliefs).

\subsubsection{Equilibrium Analysis}


The equilibrium analysis deals with the discovery and analysis of equilibrium points (Camerer 1991). He rebutted the criticism and dispelled the myths about equilibrium analysis: Firstly, game theoretic reasoning is only one of several kinds of equilibrating forces to converge to an equilibrium. Secondly, players do not necessarily think that others are rational and think others think they are rational, since there is much less rationality needed for some games to be solved. Camerer (1991) emphasized that game theoretic reasoning is a kind of cognitive tatonnement, and the following forces might similarly produce equilibration in games: introspection, communication, adaptation and evolution.

\subsubsection{The Prisoner's Dilemma and Beyond}

The Prisoner's Dilemma goes back to Von Neumann and Morgenstern (1944) and Nash (1950) with around 1000 articles written about it in the 50s and 60s (Donninger, 1986). It was made popular to the social sciences with Axelrod (1986) with alone 209 articles based on it in the 80s and 90s (Axelrod and D’Ambrosio, 1995). Whenever game theory is mentioned, the first connection made is with the Prisoner's Dilemma and the Nash Equilibrium. The Prisoner's Dilemma is the dilemma between self-interest and co-operation or altruism. Camerer (1991) gave as an example for such a Prisoner's Dilemma application in strategy that firms need to decide whether to maintain high prices or low production amounts in a cartel. It is clear that in a single play the rational self-interested players should defect, as this is a dominant strategy and it makes no difference whether the other player is rational or not. There have been many new approaches and angles to the Prisoner's Dilemma recently, in particular repetition, reputation and monitoring (Bhaskar \& Obara, 2002; Mailath \& Morris, 2006; Piccione, 2002). Graham (2003) showed in his paper the rationale behind the Prisoner's Dilemma for an IB audience using an MNE perspective.

We develop Camerer's approach by adding to his basic model a dynamic dimension, with time (t). This allows us to move from static to dynamic games. Furthermore, we add an 
information dimension, with a dummy player, called Nature, or a randomization of types, with probabilities (p). This means we can show key equilibrium concepts beyond the famous Nash Equilibrium, made with regard to the problem of the Prisoner's Dilemma. In addition to the Prisoner's Dilemma, table 1 outlines the three key equilibrium concepts developed to attend to the time and information dimensions - Subgame Perfect Equilibrium, the Bayesian Nash Equilibrium and the Perfect Bayesian Equilibrium (Harsanyi, 1967-8; Selten, 1975).

Insert Table 1: Static and Dynamic Games of Complete and Incomplete Information

\subsection{International Business Research - The Application of Game Theory to International Business}

We are now in the position to examine how far Game Theory has been applied within the International Business literature. Game Theoretic contributions to the field have been few. Table 2 positions the game theoretical IB literature into the Prisoner's Dilemma and beyond.

Insert Table 2: Situating International Business Applications of Game Theory against Key Equilibrium Concepts

The following paragraphs use the game theoretical International Business literature to show the strength of this approach and align it with the equilibrium concepts of Table 1.

Prisoner's Dilemma as static complete information game. Graham (1998) considered market structure and the role of MNEs by using a Prisoner's Dilemma situation and showed the 
oligopoly situation in a game theoretical model. He uses game theory to show important insights into why MNEs of significant are occurring in markets. His explanation elaborates about the first movers in a market and that players do not necessarily need to be low cost sellers to become MNEs. Many advantages of an MNE lead to it being a first mover, which can be more connected to its efforts to keep its rival away than its reaction to the advantages which overall entails FDIs. Graham stressed that game theory can be a very rich supplement to transaction costs to theorize phenomena in the world which are observed, but not well explained. His suggestion for applying game theory to MNEs is strong, as it shows that game theory deserves to be more appreciated in International Business.

Dynamic complete information game. Casson (1994) outlines in The Economics of Business Culture an important research agenda centring on a rigorous treatment of culture. Although he contrasts his approach with transaction cost and Game Theory, his approach can be understood as a particular form of game theorizing. He argues that Game Theory assumes contracts as unenforceable and therefore relates models of Game Theory with international relations topics in which there is no supranational authority capable of enforcing contracts. He postulates and offers a model of a follower-leader relationship for business culture relationships. In game theoretic equilibrium concept terms, this is an example of a Stackelberg equilibrium which is based on a dynamic perfect information setting. Agmon (2003) developed a stylized game theoretic model in order to gain insights into the income distributional effects of the globalization process. He emphasized the bargaining situation between national states, which are trying to generate more welfare for their residents, and MNEs which are trying to maximize their value. The author applied the model to the case of Israel and Intel. This shows a clear applicability of game theory to MNE and government relationships. Similarly, Luo (2004) analyzed a game theoretical application to international business topics such as MNEs, their relationship with governments and general international alliance issues with a cooperation and competition perspective. His book Co-opetition in International Business is based on Brandenburger and Nalebuff's (1996) Co-opetition. Sanna- 
Randaccio and Veugelers (2007) used a game theoretical approach to analyze MNE knowledge spillovers and analyzed it from an industrial organization perspective with a mathematical treatment of strategic interactions.

Static incomplete information games. Ott (2006) considered an international joint venture game for the various stages of an IJV life cycle and applied game theoretical refinements (information economics, common agency, repeated games) to the different problems of incomplete information in IJVs. Her work was based on a logical mathematical treatment of IJVs, Ott (2006) shows that moral hazard and adverse selection problems can be approached by offering incentive compatible contracts for the different strategic archetypes of IJV configurations in a special common agency game.

Dynamic incomplete information games. Adding a dynamic perspective to the Prisoner's Dilemma situation of MNEs and their $\mathrm{HQ}$ and subsidiary relationships, Zhang and Rajagopalan (2002) show a Repeated Prisoner's Dilemma game with the two players' iterated choice regarding control and cheating - a repeated moral hazard scenario. The logical analysis of the problem followed a case study. Ott (2006) added, as well, a dynamic incomplete information dimension to the adverse selection and moral hazard in the form of signaling and repeated moral hazard contracts for the strategic archetypes of IJVs.

Cooperative Games. The games applied to International Business above are more or less non-cooperative games. Rao and Reddy (1996) used game theory to analyze coalitions in strategic alliances and joint ventures. They show the strength of game theory to model problems of binding agreements and how coalitions are formed in alliances. The authors added a dynamic analysis to the basic game theoretical approach. Similarly, Ott (2006) chose a combination of cooperative and non-cooperative game theory in her common agency analysis. 
These applications to topics of international business and the respective equilibrium concepts are useful to clarify that the game theoretical analysis includes many more facets than a static, simultaneous move game like the Prisoner’s Dilemma game. It makes a strong statement about the strength of game theory as a set of methods and a way of gaining insights into the complexities, patterns and interactions in international endeavors. It shows, as all the authors above pointed out, that game theory has been so far overlooked as a theoretical tool which can generate hypotheses to be tested with data from a 'real life' context.

\section{3. $\quad$ Strength and Weaknesses of Game Theory for International Business}

The applications of game theory to international business show a clear research agenda and the possibility to use a structured, strategic and robust approach to problems in MNEs, between MNEs and governments, market access, international collaborations and cultural communication. By applying game theory to IB problems, these authors speak in a clear voice about the strength of game theory for International Business. Nevertheless, it is necessary to examine criticisms of Game Theory. This process may help to clarify some common areas of misconceptions.

This section starts with the weaknesses of Game Theory identified for Strategic Management by Ghemawat (1997) and Rumelt, Schendel and Teece (1991, pp. 18-22), transfers them into strengths and shows how International Business can circumvent them with the knowledge and techniques we now possess. We take their criticisms and show the response from Camerer (1991) and other authors in game theory, industrial organization and economics. We add an International Business perspective to it and connect it to the previously shown equilibrium concepts in order to show the strength of Game Theory for International Business.

Criticism 1. Knowledge about the strategic phenomena to be studied is outside the scope of Game Theory and game theorists are generally unwilling to learn much about business, 
leaving a leading role for scholars (presumed to be strategists) who identify phenomena worth studying. Relating this criticism to International Business, there can be a concern that game theorists do not have the knowledge about phenomena of International Business. This is a weak point. Just because game theorists have not looked at International Business it does not follow that International Business should not look at Game Theory. A dialogue between these two areas should be started and one useful way of to do this would be for International Business to grow our own International Business scholars with Game Theory knowledge. Camerer (1991) showed how game theoretical reasoning and the concern about its use in strategic management can be brushed off by a chopstick analogy in which students and scholars can use the reasoning techniques. The assumption that game theoretic models are too hard to use can be overcome by education, practice and even software.

Criticism 2. Game-theoretic analyses focus on explaining the possible existence of interactive effects rather than assaying their practical importance, which hurts predictive power. Camerer (1991) argues in favor of game theory and emphasized that it answers questions managers should want to know the answers to, and it should be part of a sensible package of advice. The best advice will come from an empirically-grounded 'behavioral game theory' that tells them how others are likely to behave. It needs to be emphasized that International Business phenomena often deal with multi-person decision-making problems and Game Theory would offer appropriate solution concepts for dealing with these real-life topics. This would lead to much stronger predictive power of strategic international interactions (in MNEs and between countries). Finally, we would like to point to the application of game theory to auctions as a good example of its applicability to practical issues and its predictive power.

Criticism 3. Game-theorists model strategic phenomena piecemeal, in a way that focuses on a minimal number of economic variables to the exclusion of others - psychology, political, organizational, technological, and even economic - which limits both scientific testability and practical utility. This critique considers the problem of using a minimal number of variables 
and neglecting those with a political, psychological and technological dimension. The appropriate response is that it depends on the skills of the Game Theory modeler to integrate parameters which can capture political, economic, technological, psychological and cultural factors. These variables would need to be positioned as measures and could easily be integrated in models as corollaries or lemmas. Rubinstein (1991) even suggested how to integrate psychological factors into game theoretical models. This could be done as part of the modeling or by introducing a machine which would feed back the choices of the players (Myerson,1991). In the next section we suggest adding the above-mentioned factors into game theoretical models in an elegant way.

Criticism 4. Game-theoretic equilibrium may be an unreasonable outcome to expect to observe in practice because of the information and the degree of rationality required to get there. The information argument here can easily be countered. Above, we have already shown that Game Theory allows for incomplete information. Furthermore, there have already been models of bounded rationality in Game Theory (Arthur, 1994; Rubinstein, 1998; Gigerenzer and Selten, 2002, Gintis, 2009). Camerer $(1991,149)$ emphasized that the criticism of game theory as assuming too much rationality of players is often misguided because strong rationality assumptions are not always needed, and equilibrium analysis could be worth doing because even bounded-rational players can reach an equilibrium by adaptation or other mechanisms. Gintis (2009) clearly pointed out in his analysis of the scientific status of the rational actor model that the archetypal rational actor model is an abstraction from individual choice behavior. First, he stressed that preferences are a function of the current state of the actor, and an ever changing developmental history. He also pointed out that the subjective prior is a function of beliefs which are socially constructed and dependent on cultural experience and social interaction and that preferences are affected by moral considerations that are situationally specific. 'Recognizing these dimensions of rational action dramatically complicates the analytical representation of rational action, but there is no alternative, if one's aim is the explanation of human behavior' (Gintis, 2009). Modeling human behavior in the 
context of cultural backgrounds is important for International Business and an evolutionary game theoretical approach would be a useful tool to improve our understanding of human interactions in an international contents. The criticism is thus dispelled by showing research potential for Game Theory in this area.

Criticism 5. While game-theoretic models of industrial organization focus on external interactions, the roots of competitive advantage may be internal. This critique, which is concerned about the lack of internal focus in game theoretical literature, can be dismissed because the Industrial Organization literature has already dealt with internal and external interactions. Saloner (1991) strongly argued that game theoretic models had had a tremendous impact on empirical research in industrial organization and held out similar prospects for strategic management. He suggested that game theory plays two different roles in empirical work: a) in developing and refining hypotheses for reduced form empirical models in which the specific structural characteristics of the models are not used, but an empirical investigation examines whether the data are consistent and b) in generating and testing structural models. Bresnahan and Schmalensee (1987) even wrote that the game theoretical developments produced a rich set of hypotheses and a powerful set of modeling techniques for IO. Rumelt et al. (1991) showed as well that commitment games in IO are those involving investment, in specific assets and excess capacity, research and development with and without spillovers, horizontal mergers and financial structure. Commitment and reputation are topics in Industrial Organization which have been tackled by game theory. Reputation has the internal focus on the description of relationships within the firm, and the collection of employee beliefs and reputations can be called its 'culture'. Siotis (1999) and Gersbach and Schmutzler (1999) developed game theoretical models for FDI spillovers in two firms and two country settings and in geographic clustering of activities. All these statements about game theory in IO are clearly applicable for an international business lens. In International Business research, the treatment of knowledge spillovers has touched on the Industrial Organization literature and showed its applicability to MNE topics in International Business 
(see Sanna-Randaccio and Veugelers, 2007). There is even more of a potential for IB when considering commitment, reputation and internal relationships in MNEs.

Camerer (1991) showed how the strengths of Game Theory could benefit strategic management. He argued that Game Theory was useful to provide a taxonomy of interactive situations and he postulated that game theoretic reasoning can be defended as a mathematical shortcut that is used by theorists to figure out where adaptive players will end up. He concluded in his paper that recent game theory (post-1970s) does not neglect dynamics, pregame communication, and it does not require the players to see the world in the same way.

Rubinstein (1991) emphasized that Game Theory is at once abstract and concrete.

'Thus, if a game in the formal sense has any coherent interpretation, it has to be understood to include explicit data on the player's reasoning processes. Alternatively, we should add more detail to the description of these reasoning procedures. We are attracted to Game Theory because it deals with the mind. Incorporating psychological elements which distinguish our minds from machines will make Game Theory even more exciting and certainly more meaningful.' (Rubinstein, 1991, p. 923)

Rubinstein's interpretation shows a way forward for International Business scholars in terms of using Game Theory to analyze interactions in multinationals, and to analyze the way that minds work. Particularly useful here would be the creation of cultural models of the mind. Such cultural cognitive schemes need to be investigated more closely in a globalized world, where learning is important.

Just as Industrial Organization and Information Economics benefited from the application of Game Theory as a rigorous treatment of their issues in a logical way, so International Business can benefit from Game Theory.

\subsection{Game Theory in International Business: A Research Agenda}


Game Theory can be applied to International Business topics via agency theory, contract/incentive theory, and bargaining/auction theory in a clear and structured approach. Using Buckley’s (2002) new research agenda for International Business, we can highlight the potential utility of applying Game Theory to topics of pressing concern for International Business. Buckley put forward the following topics:

'1. Can we explain the sequence of entry as major players in the world economy (Great Britain, US, Germany, Japan, Singapore, Korea, China)?

2. Why are different forms of company organization characteristic of cultural backgrounds?

3. In what empirical measures can we identify trends to (or away from) globalization?

4. Challenges to global capitalism' (Buckley, 2002, p. 371).

Below we give examples of these key International Business topics against the four fundamental equilibrium concepts in Game Theory introduced earlier.

Prisoner's Dilemma as static complete information games. Partner selection in international alliances often deals with co-operation and conflict. In cases where previous experience with each other exists, these partners will have a complete information situation and the Nash Equilibrium concept can be applied. International business policies between different countries or between multinationals and host governments are an ideal arena to which the Nash Equilibrium concept can be applied, too. Additionally, different forms of organization with different cultural backgrounds can be set up as a static complete information game and refined in the next stages.

Dynamic complete information games. Knowledge spillovers, negotiations in multinational firms and with host countries, can be modeled within the complete information scenarios between the players, with a sequential equilibrium. Entry games of new players in a market are ideally positioned to show dynamic games with complete information - thus Buckley's (2002) call to examine the sequence of entry of major players can be usefully responded to 
with the concept of dynamic complete information games. The sub-game perfect equilibrium concept deals with an evolutionary perspective under complete information.

Static incomplete information games. A range of information asymmetries in International Business, for instance between MNE headquarters (HQs) and subsidiaries, and between expatriate and local employees show elements of uncertainty due to differences in cultural, organizational and legal backgrounds. The adoption of agency models would help to develop a Bayesian Nash Equilibrium for uncertainties about preferences. Moral hazard, and adverse selection problems in International Business occur and these can be tackled from a corporate governance or contracting perspective. Buckley’s research agenda could be leading towards tackling uncertainty about the future major players in a globalized world in connection with hidden information and action problems.

Dynamic incomplete information games. The most complex problems of dynamics of information asymmetries can be found in MNEs and their subsidiary relationships. The evolutionary perspective in combination with uncertainty about the preferences of the players apply in an international alliance and cultural aspects of learning and adapting to new ways of organizing in MNEs and Emerging Market MNEs. On an international political level, many agreements between countries and MNEs are based on uncertainties on both sides and involve an important time dimension. Climate change and corruption issues would fall into this category as well.

The following table summarizes the key areas for future research using Game Theory.

Insert Table 3: Future Research for International Business Beyond the Prisoner’s Dilemma 
Overall, strategic international business interactions will benefit from either being game theoretically modeled or being empirically tested. The inclusion of a theoretically underpinned empirical research in International Business would contribute to a rigorous agenda and a stronger field.

3. An Example for the Application of Game Theory to International Business

This section deals with an application of game theory to a current international problem of MNE-subsidiary relationship derived from state of the art problems in the IB literature (Buckley, 2002). International business problems occur due to the geographical, organizational and cultural distance between the players and the different resources, production and development levels. The uncertainty about crucial trade and interaction issues between the players offers an ideal application of dynamic incomplete information game theory. We therefore choose to consider an MNE-subsidiary problem in International Business research which is created by the geographical and cultural distance between the players in an MNE - the HQ and subsidiaries. Uncertainty about the expertise and experience level of the host country employees needs to be tackled. We assume that there is the possibility to offer contracts for labor in a market which has a similar level of expertise in marketing or technology. There is an assumption that local staff will do better in the subsidiary, if they were exposed to international experience previously either through education or work experience. We would therefore like to assume that the subsidiary will have lower costs of adjustment to a multi-cultural environment, if the manager knows the culture of the MNE HQ. The players rely on signals to know whether they are in a stable relationship which would otherwise become costly in case of misunderstandings. The international signaling game combines incomplete information about the type of the subsidiary staff. This means the host firm employees could either have low experience levels and would need to learn about the MNE culture which could result in costly training, misunderstandings and conflict. On the other hand, the workforce and management of the 
subsidiary could have been exposed to the culture of the MNE through education and work experience. We are therefore choosing international experience as a productive signal in the set-up of MNE-subsidiary relationships. This would mean that we have the MNE offering a contract based on the years of international experience to the employees of the subsidiary. This scenario is particularly relevant for emerging market MNEs (EMNEs) going into markets which have so far not been explored by MNEs from the Triad Region or MNEs from the Triad Region going to emerging markets. Uncertainty about the employee relationships in MNEs can thus be captured in a multi-person decision-making scenario with strategic interaction.

Gintis (2009) described the generic signaling game in a clear and useful manner which would fit for our purposes. In a signaling game the first player to move has a type that is revealed to player 2 through a special signal. Player 2 will then respond with an action. The payoffs of these two players are then a function of the type and the action. The signaling game uses three players such as the player 1 , player 2 and Nature. Nature is a dummy player which begins the game by choosing the type $\mathrm{T}$ or state of affairs from a set with a probability. Player 1 observes the signal, but player 2 does not. Then, player 1 sends a signal to player 2 who chooses an action based on the signal. This sequence of events shows how easily game theoretical thinking can be applied to real-life issues. We consider first the mathematical notation and then the application to the IB problem.

Let us consider the following international signaling game $\Gamma^{\text {IntSignaling }}=\left(N ; T ;\left(\left(C_{i}^{t} \times S_{i}^{t}\right)_{t=1}^{T}, u_{i}\right)_{i \in N} ;\left(p^{t}\right)_{t=1}^{T}\right)$ where $\mathrm{T}$ is the number of stages in the game, $\mathrm{N}$ is the set of players, $C_{\boldsymbol{i}}^{t}$ is the set of moves or actions available to the player i at the end of stage t, $S_{i}^{t}$ is the set of signals or new information that player i could learn at the beginning of stage t; $p^{t}$ specifies a probability distribution over $\sum_{i \in N} S_{i}^{t}$, the set of 
combinations of player i's signal at stage t, as a function of the past history of actions and signals $\left(\sum_{t=1}^{T-1} \sum_{i \in N} C_{i}^{t} \times S_{i}^{T}\right)$ and u, specifies player i's utility payoff as a function of all actions and signals (in $\sum_{t=1}^{T} \sum_{j \in N} C_{j}^{t} \times S_{j}^{T}$ )). The time horizon T looks at two stages $\mathrm{t}=1,2$ and $C_{i}^{t}$ is the choice of incentive schemes I dependent on the signal $S_{i}^{t}$ which is years of international experience $\mathrm{y}$ in our case. The probability distribution $p^{t}$ considers the probability that the agent chooses her contracts based on the signals of years of international experience - therefore $p_{\text {INTEx }}=p\left(I \mid \bar{y}_{\text {INTEX }}\right)$. The utility payoffs are dealt with in the following sections and we can consider $u_{i}=\left\{u_{M N E} ; u_{L o c}\right\}$ as a function dependent on the history of actions and signals.

Proposition 1: If a MNE considers a manager of the host country as subsidiary manager, then the contract offered $\mathrm{I}\left(\mathrm{y}_{\mathrm{MNE}}\right)$ should be based on the agent's years of international experience in MNEs with HQs in Europe, US, Japan or emerging market.

For our game, we have the rules defined as follows: Starting with players, we have $N=\left\{\mathrm{P}_{\mathrm{MNE}}\right.$, $\left.A_{\text {Local }}\right\}$, the MNE as principal who is risk-neutral, and an agent $A_{\text {Loc }}$ who is a local firm or subsidiary employe. The agent $A_{\text {Loc }}$ will be offered contracts $I_{\text {Loc }}$ and may either accept or reject. If we consider the MNE offering incentives based on an international experience signal according to years educated or worked abroad, then we need to consider the subsidiary to provide a signal of low experience or high experience level. Since this is the ex ante stage of a contractual setting, this special game could provide a solution to contractual uncertainties in the set-up phase of MNE-subsidiary relationships. In terms of incentives, many ways of offering are possible. We consider incentives to encourage co-operation (Holmstrom, 1979; Guesnerie and Laffont, 1984; Geringer and Woodcock, 1995; Campbell, 1997; Levin, 2003; 
Andreoni et al. 2003, Ott, 2006). The outcome of the game is either a pooling equilibrium or separating equilibrium which are both part of the Perfect Bayes' equilibrium (PBE) concept. In the appendix the mathematical solutions to our problem are presented, whereas the game tree and the intuitive results for IB problems can be seen in this section.

Proposition 2. If there are the pooling and the separating equilibria, then the former occurs when both types pretend to be a low type and the latter is advantageous if both types have incentive compatible outcomes. It would not pay a low type to pretend to be a high type and vice versa. In some cases, a low experience type might pretend to be a high type to get the higher payment. Thus, the incentive schemes may have to be developed so that it is difficult to lie about one’s type and truth-telling becomes a dominant strategy.

The two propositions are mathematically dealt with in the appendix as proofs, whereas the game tree shows the moves of the players in a perfect Bayesian equilibrium.

Figure 1: Game tree of the Signaling Game in MNE with host's experience levels

The pooling equilibrium reflects that a subsidiary agent would like to pretend to be a high type agent (even so he might not have the experience level), which would result in a higher payment to compensate for his experience (Scenario 2) or to be a low type while actually being a high type agent (Scenario 3) in order to benefit from training for instance. The following two pooling scenarios are dealt with to show the different motivations behind the moves of the players and the resulting ways to move to equilibrium behavior due to the incentives offered. 
Scenario 2 (Low Type pretends to have experience to get higher payment): If the local agent pretends to be of high type, the efforts and costs will be expected to be higher as well. This would be very costly for a low type, since the high type would get paid according to his ability.

Scenario 3 (High Type pretends to have less experience to get training): Pretending to be a low type would lead to lower payment, but support in terms of training as the only incentive to pretend to be of low type. There might be other reasons for pretending to be of low type which is particularly relevant in collective cultures when the group interest might be jeopardized.

Overall, this means that high type agents would prefer to get paid according to years of experience, since the costs are related to their experience level. This is more beneficial than pretending to have less experience and getting a lower payment while the costs are still the same. Whereas, a low type should prefer to get paid according to their experience level, since in the higher payment case the effort level will be expected to be higher anyway.

In a separating equilibrium both types of agents are required and encouraged to tell the truth due to the design of the incentive scheme.

Scenario 1: It pays off to be a low type and reveal the years of experience for a low type, since the disutility of effort is beneficial for the low type.

Scenario 4: Shows that a high type with a lot of international experience would not benefit from behaving as a low type. The Mathematical Appendix deals with the combination of incentive schemes and shows a MNE-subsidiary signaling game.

We can follow the model and use costs of experience and disutility of efforts. Given the different players in a MNE, let us now present the following table in which the subsidiary is player 1 and the MNE HQ is player 2 with their respective strategies and equilibria. The 
Table 4 shows how the years of experience influence the contracts offered by the MNE as a result of the pooling and separating equilibria (mathematically analyzed in the appendix).

Insert Table 4 here: MNE-subsidiary signaling outcomes

The design of the relevant contracts and incentive schemes leads to the revelation about the type of players in a MNE-subsidiary relationship. The transfer into an international business arena helps to show the logic and the solution behind those dilemmas and tensions in MNE scenarios. We were able to see that with an incomplete information scenario and a dynamic approach, we are giving a theoretical underpinning for empirical research. Furthermore, from an evolutionary perspective found in Gintis (2009), these problems can as well be solved with evolutionary game theory which would have strong implications for IB research.

\section{Conclusion}

This paper has shown that referring only to the Prisoner’s Dilemma when talking about Game Theory and International Business is not enough. Besides the Nash Equilibrium which shows co-operation and conflict in a static and complete information setting, there are three more game theoretical equilibrium concepts which contribute to the strength of game theoretical research in many disciplines and fields: Subgame Perfect Equilibrium (dynamic complete information games), Bayesian Nash Equilibrium (static incomplete information games) and Perfect Bayesian Equilibrium concepts (dynamic incomplete information games). This paper has used the four equilibrium concepts to position the seminal work in Game Theory, to revisit the game theoretical work in International Business and to suggest a future research agenda for Game Theory in International Business. 
The paper dealt with the criticism often put forward when Game Theory is concerned. It rebutted the general misconceptions and criticism by showing the advantages and strengths from renowned scholars in the field of game theory, industrial organization, evolutionary economics, strategic management and international business itself. IB scholars have used game theory to show strategic and cultural interactions in MNEs, IJVs, between MNEs and governments which emphasized the applicability to IB problems. Game Theory has not found its support in a wider circle due to some misconceptions which this paper has hoped to dispel.

A future research agenda put forward by IB scholars was combined with a game theoretical treatment of a signaling game of MNE-subsidiary relationships in which signaling is an important factor to achieve an optimal solution. The propositions of the models are analyzed in pooling and separating equilibria which have as an important finding that the international experience of the players is a relevant signal for the stability in an MNE. The analysis focused on a factor which has been so far not very much theoretically explored. There would be a lot of potential for empirical investigations into the strategic HQ-subsidiary relationships when it comes to self-interest and cooperation. The propositions show that the signals of the subsidiary sent to the HQ can lead to either a pooling or separating equilibrium when the host player has an interest to pretend to be either a different (lying) type or the true type. The HQ can develop incentive schemes which are a response to the signal. The design of incentive schemes in IB is here considered as dependent on international experience which is important for an MNE.

One limitation of the paper is that we have based our model on a hypothetical problem derived from the IB research agendas. An empirical test, however, would be outside of the scope of the paper. Future research could actually use data and analyze it on an abstract game theoretical level, but also apply the game theoretical and contractual insights of an abstract model to data collected in international business settings. Game Theory offers many useful concepts to apply to the wealth of empirical data in the laboratory of International Business. 
Our contribution is to point to future research which combines a game theoretical analysis with empirical investigations to benefit from a mixed methods approach and to come up with a rigorous treatment of problems in international business. International Business would clearly benefit from a game theoretical perspective on issues of pressing current relevance. Problems of strategic interactions, co-operation and conflict between countries, MNEs, HQs and subsidiaries as well as individuals of different cultural backgrounds, are all multi-person decision-making scenarios ideally suited for the application of Game Theory. The uncertainties in international business can be dealt with via incomplete information games and evolutionary issues can be dealt with via dynamic games. In order to fully benefit from the strong theoretical tool that is Game Theory, the field of International Business would need to accept Game Theory's approach towards the role of reasoning and to modeling interaction between multiple parties, cultures, organizational and knowledge levels.

To return to Camerer (1991) and his call, two decades ago, for an engagement by Strategic Management scholars with Game Theory, it is worth noting that Game Theory has now become well-established in Strategic Management. This field of management is now much stronger for this development. It might therefore be that International Business would similarly benefit from a more consistent treatment of strategic interactions between the global players in International Business. 


\section{REFERENCES}

Agmon, T. (2003). Who gets what: the MNE, the national state and the distributional effects of globalization, Journal of International Business Studies, 34, 416-427.

Akkermans, D, Harzing, A.W. \& Witteloostuijn, A van (2010). Cultural Accommodation and Language Priming. Competitive versus Cooperative Behavior in a Prisoner's Dilemma Game, Management International Review, 50: 559-584.

Andreoni, J., Harbaugh, W. \& Vesterlund, L. (2003). The carrot or the stick: Rewards, punishment and cooperation, The American Economic Review, 93, 893-902.

Arthur, W. Brian (1994) Inductive Reasoning and Bounded Rationality. The American Economic Review, 84(2), pp. 406-411.

Axelrod, R. (1984). The Evolution of Co-operation. New York: Basic Books.

Axelrod, R. and D’Ambrosio, L. (1995). Announcement for Bibliography on the Evolution of Cooperation, Journal of Conflict Resolution, 39: 190.

Bhaskar, V. \& Obara, I. (2002). Belief-Based Equilibria: The Repeated Prisoner’s Dilemma with Private Monitoring, Journal of Economic Theory 102: 40-69.

Bicchieri, C. (2006). The Grammar of Society: The Nature and Dynamics of Social Norms. Cambridge: Cambridge University Press.

Brandenburger, A. \& Nalebuff, B. (1996). Co-opetition. Profile Books.

Buckley, P. (2002). Is the International Business Research Agenda Running out of Steam? Journal of International Business Studies, 33, 365-373.

Camerer, C. F. (1991). Does Strategy Research need Game Theory? Strategic Management Journal, 12, 137-152.

Casson, M. C. (1994) The Economics of Business Culture: Game Theory, Transaction Costs and Economic Performance, Oxford University Press.

Casson, M. C. (2000). The Economics of International Business, Edwar Elgar. 
Donninger, C. (1986). Is it always efficient to be nice? In Dickman and Mitter (eds), Paradoxical Effects of Social Behavior, Heidelberg: Physica Verlag, p. 123-134.

Gersbach, H. \& Schmutzler, A. (1999). External spillovers, internal spillovers and the geography of production and innovation, Regional Science and Urban Economics, 29: 679-696.

Ghemawat, P. (1997). Games Businesses Play. Cambridge, MA: MIT Press.

Gigerenzer, G. \& Selten, R. (2002) Bounded Rationality: The Adaptive Toolbox. Cambridge MA: MIT Press.

Gintis, H. (2009). Game theory evolving. Princeton: Princeton University Press.

Graham, E. M. (1998). Market Structure and Multinational Enterprise: A Game Theoretic Approach, Journal of International Business Studies, 29, 67-83.

Harsanyi, J. (1967-8). Games with incomplete information played by Bayesian players, Management Science, 14, 159-82, 320-34, 486-502.

Levin, J. (2003). Relational incentive contracts, The American Economic Review, 93, 835857.

Luo, Y. (2004). Co-opetition in Multinationals, Copenhagen: Copenhagen Business School Press.

Mailath, G.J. \& Morris, S. (2006). Coordination Failure in Repeated Games with almostpublic Monitoring, Theoretical Economics 1: 311-340.

Mirrlees, J. (1971). An Exploration in the Theory of Optimum Income Taxation, Review of Economic Studies, 38(2): 175-208.

Myerson, R. B. (1991). Game Theory: Analysis of Conflict, Cambridge MA: Harvard University Press.

Nash, J. (1950) The Bargaining Problem, Econometrica, 18(1), 155-62.

Nash, J. (1951) Noncooperative Games, Annals of Mathematics, 54: 289-95.

Nash, J. (1953) Co-operative Games, Econometrica, 21, 128-40.

Ott, U. F. (2006) International Joint Ventures: An Interplay of Co-operative and NonCooperative Games under Incomplete Information, Basingstoke: Palgrave Macmillan. 
Piccione, M. (2002). The Repeated Prisoner's Dilemma with Imperfect Private Monitoring, Journal of Economic Theory 102: 70-83.

Rao, B.P.\& Reddy, S.K. (1996). A dynamic approach to the analysis of strategic alliances, International Business Review, 4, 499-518.

Rasmusen, E. (1994). Games and Information, Cambridge MA: Blackwell.

Ring P. S. \& Van de Ven, A. (1994). Developmental processes of cooperative interorganizational relationships, Academy of Management Review, 19, 90-118.

Rubinstein, A. (1991) Comments on the Interpretation of Game Theory, Econometrica, 59, 909-924.

Rubinstein, A. (1998). Modeling Bounded Rationality. Cambridge MA: MIT Press.

Rumelt, R., Schendel D. \& Teece, D. J. (1991). Strategic Management and Economics, Strategic Management Journal, 12, 5-29.

Saloner, G. (1991). Modeling, Game Theory, and Strategic Management, Strategic Management Journal, 12, 119-136.

Schelling, T. C. (1960). The Strategy of Conflict. Cambridge: Harvard University Press.

Selten, R. (1960). Spieltheoretische Behandlung eines Oligopolmodells mitNachfragetragheit, Zeitschrift fur die gesamte Staatswissenschaft 121, 301-24 and 667-89.

Selten, R. (1978). The Chain Store Paradox, Theory and Decision, 9, 127-159.

Sanna-Randaccio, F. and Veugelers, R. (2007) Multinational knowledge spillovers with decentralized R\&D: A game theoretic approach, Journal of International Business Studies, 38, 47-63.

Shenkar, O. \& Yan, A. (2002). Failure as a consequence of partner politics: learning from the life and death of an international cooperative venture, Human Relations, 55, 565-601.

Siotis, G. (1999). Foreign direct investment strategies and firms capabilities, Journal of Economics and Management Strategy, 8: 251-270.

Spence, M. (1973). Job Market Signaling. Quarterly Journal of Economics, 87,355-79.

Stigler, G. J. (1961). The Economics of Information, Journal of Political Economy, 69. 
Vickrey, W. (1961). Counterspeculation, Auctions and Competitive Sealed Tenders, ,Journal of Finance, 16, 41-50.

Von Neumann, J. \& Morgenstern, O. (1944). The Theory of Games and Economic Behavior (Princeton, NJ: Princeton University Press.

Zhang, Y. \& Rajagopalan, N. (2002). Inter-partner Credible Threat in International Joint Ventures: An Infinitely Repeated Prisoner’s Dilemma Model, Journal of International Business Studies, 33, 457-478.

References added:

Axelrod (1984) see in references

Graham (1998) see in references

Bresnahan, T. F. \& Schmalensee, R. (1987). The Empirical Renaissance in Industrial Economics: An Overview, Journal of Industrial Economics, 35, 371-78.

Selten, R. (1975). Reexamination of the perfectness concept in Nash equilibrium points in extensive form games, International Journal of Game Theory, 4, 25-55.

Campbell, D. E. 1997. Incentives - Motivation and the Economics of Information,Cambridge University Press, Cambridge, UK.

Geringer, J. Michael, and C. Patrick Woodcock. 1995. Agency costs and the structure and performance of international joint ventures. Group Decision and Negotiation, 4: 453-467.

Guesnerie, Roger, and Jean-Jacques Laffont. 1984. A complete solution to a class of principal-agent problems with an application to the control of a self-managed firm. Journal of Public Economics., 25: 329-369.

Holmstrom, Bengt. 1979. Moral hazard and observability. Bell Journal of Economics, 10: 7491.

Stigler, G. J. (1961). The Economics of Information, Journal of Political Economy, 69, 213225. 
TABLES:

Table 1: Static and Dynamic Games of Complete and Incomplete Information

\begin{tabular}{|l|l|l|}
\hline Games & Complete Information & Incomplete Information \\
\hline Static Games & $\begin{array}{l}\text { Nash Equilibrium } \\
\text { Prisoner's Dilemma, } \\
\text { Nash (1950,1952) }\end{array}$ & $\begin{array}{l}\text { Bayesian Nash Equilibrium } \\
\text { Harsanyi (1967-8) }\end{array}$ \\
\hline Dynamic Games & $\begin{array}{l}\text { Subgame Perfect Equilibrium } \\
\text { Selten (1975) }\end{array}$ & $\begin{array}{l}\text { Perfect Bayesian Equilibrium } \\
\text { Harsanyi (1967-8) }\end{array}$ \\
\hline
\end{tabular}

Source: Ott (2006)

Table 2: Situating International Business Applications of Game Theory against Key Equilibrium Concepts

\begin{tabular}{|l|l|l|}
\hline $\begin{array}{l}\text { Authors in IB (in } \\
\text { alphabetical order) }\end{array}$ & Prisoner's Dilemma & $\begin{array}{l}\text { Beyond the Prisoner's } \\
\text { Dilemma }\end{array}$ \\
\hline Agmon (2003) & Government - MNE & \\
\hline Akkermans et al (2010) & Cultural Accommodation & \\
\hline Casson (1994) & MNE - Market Equilibrium & $\begin{array}{l}\text { Leader-Follower Model } \\
\text { Stackelberg }\end{array}$ \\
\hline Graham (1998), & Government - MNE & $\begin{array}{l}\text { IJVs and Incomplete } \\
\text { Information }\end{array}$ \\
\hline Luo (2004) & & Strategic Alliances \\
\hline Ott (2006) & & $\begin{array}{l}\text { Knowledge Spill-Overs in } \\
\text { MNE }\end{array}$ \\
\hline Rao and Reddy (1996) & $\begin{array}{l}\text { Iterated Prisoner's Dilemma } \\
\text { within IJVs }\end{array}$ & \\
\hline $\begin{array}{l}\text { Sanna-Randaccio and } \\
\text { Veugelers (2007) }\end{array}$ & & \\
\hline Zhang and Rajagopalan & & \\
\hline
\end{tabular}


Table 3: Future Research for International Business Beyond the Prisoner’s Dilemma

\begin{tabular}{|l|l|l|}
\hline Games & Complete Information & Incomplete Information \\
\hline Static Games & Prisoner's Dilemma & Bayesian Nash Equilibrium \\
& $\begin{array}{l}\text { Partner Selection in International } \\
\text { Alliances; } \\
\text { Global Climate Change Policies }\end{array}$ & $\begin{array}{l}\text { Information Asymmetries between } \\
\text { MNE HQs and hosts } \\
\text { Emerging MNEs }\end{array}$ \\
\hline Dynamic Games & Subgame Perfect Equilibrium & Perfect Bayesian Equilibrium \\
& $\begin{array}{l}\text { Industrial Organization Topics, } \\
\text { Knowledge Spillovers, } \\
\text { Negotiations in MNEs } \\
\text { Emerging markets MNEs }\end{array}$ & $\begin{array}{l}\text { Dynamics of information } \\
\text { asymmetries in MNE - subsidiary } \\
\text { relationships } \\
\text { Emerging markets MNEs }\end{array}$ \\
\hline
\end{tabular}

Table 4: Pooling and Separating Equilibria in MNE-subsidiary relationships

\begin{tabular}{|c|c|c|c|}
\hline & \multicolumn{2}{|c|}{ HQ -MNE (Principal) } \\
\hline & & $\begin{array}{l}\text { Incentive Scheme for low } \\
\text { experience level (few } \\
\text { years) } \\
\text { y }_{\mathrm{MNE}}<\text { g contract } \mathrm{I}_{\mathrm{L}}\left(\mathrm{y}_{\mathrm{MNE}}\right)\end{array}$ & $\begin{array}{l}\text { Incentive Scheme for high } \\
\text { experience level (many } \\
\text { years) } \\
\text { y }_{M N E} \geq \text { g for } \mathrm{I}_{\mathrm{H}}\left(\mathrm{y}_{\mathrm{MNE}}\right)\end{array}$ \\
\hline \multirow[t]{2}{*}{$\begin{array}{l}\text { Subsidiary } \\
\text { Local Host } \\
\text { Employee } \\
\text { (Agent) }\end{array}$} & $\begin{array}{l}\text { Low } \\
\text { experience } \\
\text { level (few } \\
\text { years) in case } \\
\text { of SMEs with } \\
\text { technology }\end{array}$ & $\begin{array}{l}\text { Low Local /Low MNE } \\
\text { Both know that player } 1 \\
\text { needs to learn and player } 1 \\
\text { is telling the truth, since } \\
\text { the incentive is offered for } \\
\text { a low type. } \\
\text { Learning of cultures is at } \\
\text { the centre with cross- } \\
\text { cultural training facilities } \\
\text { to be provided for low } \\
\text { types } \\
\text { Scenario (1) Separating } \\
\text { Equilibrium }\end{array}$ & $\begin{array}{l}\text { Low Local High MNE } \\
\text { Local firm does not have a } \\
\text { lot of international } \\
\text { knowledge; high costs of } \\
\text { learning for subsidiary } \\
\text { employee, but expectation of } \\
\text { employee is higher than } \\
\text { what can be delivered - } \\
\text { short-lived } \\
\text { Scenario (2) } \\
\text { Pooling Equilibrium }\end{array}$ \\
\hline & $\begin{array}{l}\text { High } \\
\text { experience } \\
\text { level (many } \\
\text { years) }\end{array}$ & $\begin{array}{l}\text { High Local/Low MNE } \\
\text { MNE offers low incentive } \\
\text { schemes to someone with } \\
\text { high experience level; } \\
\text { MNE gets market access } \\
\text { and high-skilled labor, but } \\
\text { does not reciprocate - } \\
\text { short lived } \\
\text { Scenario (3) Pooling } \\
\text { Equilibrium }\end{array}$ & $\begin{array}{l}\text { High Local/High MNE } \\
\text { The high type agent will } \\
\text { get the incentive scheme } \\
\text { which fits the expertise } \\
\text { and costs as well effort } \\
\text { levels. } \\
\text { Success - Case } \\
\text { Co-operation of both } \\
\text { Scenario (4) } \\
\text { Separating Equilibrium }\end{array}$ \\
\hline
\end{tabular}




\section{FIGURES:}

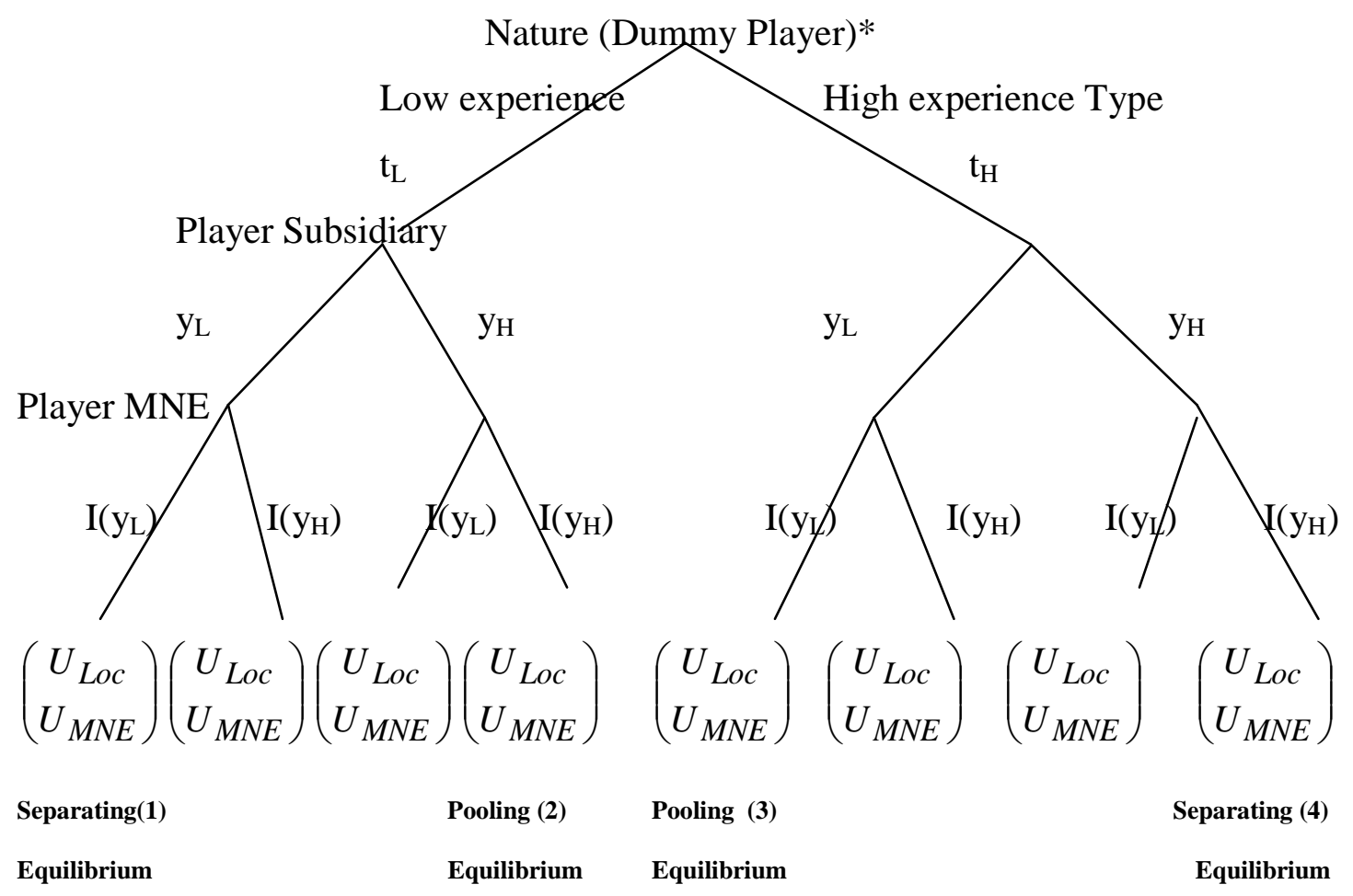

Figure 1: Game tree of the Signaling Game in MNE with host's experience levels

*Nature: is a Dummy Player which knows the type of player 1 and player 1 learns their type from Nature which randomizes the choices. 
GLOSSARY OF GAME THEORETICAL TERMS (Camerer 1991, 151-152):

Nash Equilibrium: An NE occurs when each player's action is rational given the other player's equilibrium action.

Pooling Equilibrium: occurs when players with different privately-known information or utilities (different 'types') choose the same action;

Separating Equilibrium: occurs when they choose different actions.

Rationalizable strategies: are those which are optimal, for some beliefs about the choices others are likely to make, provided one does not expect others to choose a dominated strategy. Dominated Strategy: is a strategy which is never better and sometimes worse than another strategy.

Dominant Strategy: is a strategy which is better than another strategy.

Coordination Games: are those games with multiple equilibria - the battle of the sexes is an example - in which players strive to agree on one equilibrium because out-of-equilibrium responses hurt everyone.

Reputation: in game theory is the common perception of another player's privately-known type.

Trigger Strategy: in a repeated game is a strategy which chooses an action that punishes another player for breaking an unspoken agreement, tit-for-tat is one well-known example.

Folk Theorem: is a group of theorems showing that in repeated games, virtually any outcome can be sustained as an equilibrium. 


\section{MATHEMATICAL APPENDIX}

\section{Incentives and signaling}

Suppose we have flat fee payments for two types (low or high quality level), the incentive is independent of any kind of performance or other variable factor. Thus, payment for low quality may be $\mathrm{I}_{\mathrm{L}}=\mathrm{I}$ and $\mathrm{I}_{\mathrm{H}}=2 \mathrm{I}$ for the high type. A refinement of contracts and a method of taking into consideration the ex ante judgment of the agent's quality can be applied by offering incentives dependent on years of experience in international ventures.

To start with a signaling problem, the agent might have gained multinational enterprise (MNE) experience through various international assignments. The payment offered could, therefore, be based on the years of such international experience. The agent might be a lowtype or a high-type of quality. Since the economy can be divided into a fraction of firms being of superior type, the contracts may be designed to target these differences in types. The contract $\mathrm{I}_{\mathrm{HCN}}$, incentive contract for host country nationals $(\mathrm{HCN})$, could therefore have the following nature that it is dependent on years of experience in the MNE culture $\mathrm{y}_{\mathrm{MNE}}: \mathrm{I}_{\mathrm{HCN}}=$ $\mathrm{I}\left(\mathrm{y}_{\mathrm{MNE}}\right)$.

Lemma 1: The distinction between the two types can be made by introducing a cut-off point experience level g such as $\mathrm{y}_{\mathrm{MNE}}<\mathrm{g}$ stands for the low quality type and $\mathrm{y}_{\mathrm{MNE}} \geq \mathrm{g}$ for the high type. There is $g=[\underline{g}, \bar{g}]$

$\mathrm{I}_{\mathrm{HCN}}=\mathrm{I}\left(\mathrm{y}_{\mathrm{MNE}}\right) \quad$ years of MNE experience where $\mathrm{g}$ is a critical value as 
experience strategy $\left\{\begin{array}{l}y<\mathrm{g} \text { for } \mathrm{I}^{\mathrm{L}}=0 \\ \mathrm{y} \geq \mathrm{g} \text { for } \mathrm{I}^{\mathrm{H}}=1\end{array}\right.$

Turning to the case of a scheme based on MNE experience, the principal could develop a flat fee $\mathrm{I}_{\mathrm{HCN}}=\mathrm{I}$ for the low type and $\mathrm{I}_{\mathrm{HCN}}=$ 2I for the high type, therefore $\mathrm{I}_{\mathrm{HCN}}$ is independent of years of international experience.

Proposition 1: If a MNE considers a manager of the host country as subsidiary manager, then the contract offered $\mathrm{I}\left(\mathrm{y}_{\mathrm{MNE}}\right)$ should be based on the agent's years of international experience in MNEs with HQs in Europe, US, Japan or emerging market.

In the case of the HQ offering incentives to the local manager (HCN) who could have experience in MNEs in order to provide the subsidiary with knowledge about international transactions and to make a successful contribution to an international business venture, we have the following incentive scheme

Since the principal can choose the agent based on his critical value $\mathrm{k}$ in relation to the experience level, the case will be analogous to the scenario above.

Let us consider the two types of agents and the contracts offered by the principal. Thus, we have the following payoffs for the agents and the individual rationality constraints

$u_{H C N}^{S u b}=I_{H C N}\left(y_{M N E}\right)-v\left(e_{M N E}\right)$ or $\quad u_{H C N}^{S u b}=I_{H C N}\left(y_{M N E}\right)-c\left(y_{M N E}\right)$

where

$u_{M N E}^{S u b} \geq 0$ is IR constraint 
Since $v\left(e_{H C N}\right)=c\left(y_{M N E}\right)$ is considered as disutility of effort and costs of experience which means that the managers have lower costs and efforts when they have higher experience levels. A key assumption is that $\mathrm{c}_{\mathrm{H}}(\mathrm{y})<\mathrm{C}_{\mathrm{L}}(\mathrm{y})$, it is more costly for a low quality type to achieve a given experience level because a low type has to put in more effort. More years of experience will induce low effort costs. Now, consider $I\left(y_{M N E}\right)$ as value of the marginal product. If $\tau$ is increasing with y then the productivity increases with experience $I_{H}\left(y_{M N E}\right)>I_{L}\left(y_{M N E}\right)$.

Another type of linear contract can be found in connection with royalties and fixed payments. The principal offers a high fixed payment plus a low royalty depending on the output or performance for the low quality agent and vice versa. Agents have to disclose their skills by choosing a contract. Since it is possible to lie about ones qualities, the contracts have to be designed in a way that they fulfill participation and the incentive compatibility constraint such that it is difficult to accept a contract which is not appropriate. Under the assumption that truth-telling is a dominant strategy, the revelation principle can be introduced for problems of signaling.

Proposition 2. If there are the pooling and the separating equilibria, then the former occurs when both types pretend to be a low type and the latter is advantageous if both types have incentive compatible outcomes. It would not pay a low type to pretend to be a high type and vice versa. In some cases, a low experience type might pretend to be a high type to get the higher payment. Thus, the incentive schemes may have to be developed so that it is difficult to lie about one’s type and truth-telling becomes a dominant strategy. 
Since these schemes are optional, the menus of contracts are applied to incomplete information games in the start-up phase of a MNE-subsidiary relationship between players without former business experience. These cases occur especially in dyadic country combinations, e.g. one parent is in a less developed or developing country with strict host government rules and the other one from an industrialized country, desiring market access.

Pooling Equilibrium. Suppose now that the years of MNE experience are productive, $I_{L}\left(y_{M N E}\right)=r y+F$ and $I_{H}\left(y_{M N E}\right)=2 r y+F$, in which $\mathrm{F}$ is a nonnegative constant. The value added increases with y, but an additional unit of higher experience adds twice as much to the productivity of a high type, compared to a low type. The cost functions are such that $c_{H}\left(y_{M N E}\right)<c_{L}\left(y_{M N E}\right)$. If we assume that low types would pretend to be a high type because they prefer to get higher payment even if the costs are higher, than we have to consider the following.

Both types choose $\mathrm{y}_{\mathrm{MNE}}$ years of experience, with the critical value to be determined. Each agent is paid the same incentive scheme, the expected value of marginal product when everyone sets $\mathrm{y}_{\mathrm{MNE}}=\mathrm{g}$.

Let $\mathrm{p}_{\mathrm{H}}$ be the probability that the agent is of the high type. The expected productivity at $\mathrm{y}_{\mathrm{MNE}}$ $=\mathrm{g}$ is

$p_{H} I_{H}(g)+\left(1-p_{H}\right) I_{L}(g)=p_{H}(2 r g)+\left(1-p_{H}\right)(r g)$

The incentive scheme offered by the principal could be therefore:

If $\mathrm{y}_{\mathrm{MNE}}<\mathrm{g}$, the low type agents get payment ry $\mathrm{y}_{\mathrm{MNE}}$

If $\mathrm{y}_{\mathrm{MNE}} \geq \mathrm{g}$, the high type agents get payments $p_{H}(2 r g)+\left(1-p_{H}\right)(r g)$ 
Separating Equilibrium. Suppose the high type agent obtains more experience than the low type. The low type agents would prefer to set their years of experience on a high level to get better payments. Therefore, everyone would choose a higher number of years.

Separation requires that the agents' choice reveals their type. Thus, an agent choosing $y_{M N E}^{L}$ will receive a payment of $r y_{M N E}^{L}$ and an agent choosing $y_{M N E}^{H}$ will receive $2 r y_{M N E}^{H}$. The incentive compatibility constraints (ICC) for the separating equilibrium are therefore:

$2 r\left(y_{M N E}^{H}\right)-c_{H}\left(y_{M N E}^{H}\right) \geq r\left(y_{M N E}^{L}\right)-c_{H}\left(y_{M N E}^{L}\right)$

$r\left(y_{M N E}^{L}\right)-c_{L}\left(y_{M N E}^{L}\right) \geq 2 r\left(y_{M N E}^{H}\right)-c_{L}\left(y_{M N E}^{H}\right)$ 